\title{
22. LABORATORY MEASUREMENT OF VELOCITY VS. EFFECTIVE STRESS IN THRUST FAULTS OF THE OREGON ACCRETIONARY PRISM: IMPLICATIONS FOR FAULT ZONE OVERPRESSURE ${ }^{1}$
}

\author{
Harold J. Tobin, ${ }^{2}$ J. Casey Moore, ${ }^{2}$ and Gregory F. Moore
}

\begin{abstract}
Seismic reflection profiles of many accretionary prisms, including the Oregon prism in the Leg 146 region, exhibit highamplitude, negative-polarity reflections from the décollement and other thrusts. Previous workers have suggested that these reflections image fault zones with enhanced fluid content due to dilation by very high fluid pressure. We collected samples within the frontal thrust zone and wall-rock sediments at Site 891, and from the out-of-sequence thrust and walls at Site 892 in order to evaluate this hypothesis experimentally. We present measurements of ultrasonic $P$-wave velocity as a function of confining pressure and fluid pressure (i.e., effective stress) on samples of the Oregon frontal thrust. These data show that (1) velocity decreases by $8 \%$ to $18 \%$ as fluid pressure rises from hydrostatic to lithostatic conditions under constant confining pressure; and (2) this effect occurs in fault zone and wall rock alike, with very similar velocity vs. effective stress relationships.

We use these velocity vs. effective stress curves to calibrate the Site 891 frontal thrust reflection to fluid pressure. Synthetic waveform modeling of the frontal thrust reflection wavelet at Site 891 shows that it is the result of a thin low-velocity zone, probably less than $10 \mathrm{~m}$ thick, in the plane of the fault. Models employing relative amplitude scaling of the seafloor and fault zone reflectors indicate that the thin, low-impedance zone is $100-300 \mathrm{~m} / \mathrm{s}$ slower than the walls, if the impedance contrast is dominated by velocity. Combining models with experimental results, we conclude that fluid pressure of $86 \%$ to $98 \%$ of lithostatic pressure reduces velocity enough to generate the reflections, if the impedance reduction of the fault zone is indeed due to fluid-pressure-induced unloading. Porosity data collected during testing of a sample from the frontal thrust zone indicates that little porosity change accompanies velocity reduction except at very high pore pressures (very low effective stresses), calling into question assumptions that low velocity necessarily implies high porosity or permeability in the fault zone.
\end{abstract}

\section{INTRODUCTION}

Fluid pressure that is substantially elevated above hydrostatic conditions in the décollement and other thrust faults of accretionary prisms has been widely inferred over the past decade, but quantitative estimates of the degree of overpressuring involved have proved elusive. Ever since the work of Hubbert and Rubey (1959), it has been widely known that pore-fluid pressure is a critical parameter, governing the structural geometry and fault mechanics of the prism. Fluid pressure conditions and gradients also control fluid flow, and thereby influence the geochemical evolution of the sediments and pore fluids (Kastner et al., 1991; Moore and Vrolijk, 1992). Despite this long appreciation of the role of fluid pressure and more than a decade of intensive research, the understanding of pressure conditions in prisms has remained mostly qualitative. Results of attempted direct observation of fluid pressure in accretionary prisms or their basal décollements prior to Leg 146 have been equivocal at best (Moore and Vrolijk, 1992).

For these reasons, determination of the fluid pressure conditions in the active fault zones of the Cascadia accretionary prism was a major objective of Leg 146 drilling. Direct observation through packer testing was partially successful at Site 892 , but fluid pressure determinations may have been influenced by drilling disturbance due to

'Carson, B., Westbrook, G.K., Musgrave, R.J., and Suess, E. (Eds.), 1995. Proc. ODP, Sci. Results, 146 (Pt. 1): College Station, TX (Ocean Drilling Program).

${ }^{2}$ Earth Sciences Department, University of California, Santa Cruz, CA 95064. U.S.A.

${ }^{3}$ Department of Geology and Geophysics, University of Hawaii, Honolulu, HI 96822, U.S.A. pumping and circulation (Screaton et al., this volume). Unfortunately, isolation and hydrologic testing of the frontal thrust zone (Site 891) was not possible on Leg 146 because of poor drilling conditions, so no direct data are available on the fluid pressure in the frontal thrust zone itself, where initial accretion of the fluid-rich sediments occurs today.

The acquisition of high-quality multichannel seismic (MCS) reflection data in recent years has greatly enhanced the imaging of fault-plane reflectors from accretionary wedges globally, and has permitted detailed waveform and amplitude study of those reflections. In the Nankai (G.F. Moore et al., 1990), Barbados (Westbrook et al., 1988), Costa Rica (Shipley et al., 1990), and Cascadia (MacKay et al., 1992; Moore et al., 1991) accretionary prisms, high-amplitude, negative-polarity reflections have been recognized at the basal décollements and on other major thrust faults. Modeling of these reflections suggests that they are of two significantly different types. The first type includes those reflections produced by a simple boundary of higher impedance (velocity multiplied by density) material overlying lower impedance material, caused by underthrusting. Examples where modeling of the fault-plane reflections indicate they are dominantly of this type include the Nankai prism in the Leg 131 area (Moore and Shipley, 1993) and the Costa Rica margin (Shipley et al., 1990).

The second type is a more complex compound reflection resulting from a fault zone of finite thickness, composed of lower impedance material sandwiched between higher impedances above and below. If this low-impedance zone is thinner than the seismic wavelength, then the result will be a single, compound, reflected wavelet formed of constructively interfering pulses from the top and bottom impedance boundaries. For example, modeling of the negative polarity areas of 
the Northern Barbados Ridge décollement reflection signature shows that they are dominantly the result of this second scenario (Bangs and Westbrook, 1991; Shipley et al., 1994).

This indication that at least some of these reflections are generated by fault zones of anomalously low velocity and/or density is in some ways a puzzling conclusion. In general, the shear strain at the décollement or frontal thrust is expected to cause a collapse of fabric in the clay-dominated sediments, leading to porosity loss and velocity and density increase (Bray and Karig, 1985). Cloos (1984) first proposed that the pervasive fracture systems of wedge thrusts could be highporosity, fluid-filled zones of low acoustic impedance, dilated and kept open by near lithostatic pore pressure. Bangs and Westbrook (1991), Shipley et al. (1994), and Moore et al. (1991) have used this concept to explain the apparent paradox, speculating that, although the fault zone sediments might or might not be tectonically overconsolidated, elevated pressure in fluid migrating along the fault causes dilation of the fractures, and the net result is overall low impedance in the fault.

It is well established experimentally for lithified sedimentary rocks in general that $P$-wave velocity $\left(V_{p}\right)$ decreases with decreasing effective stress $\left(\sigma_{\text {eff }} ;\right.$ Bourbié et al., 1987). Karig (1993) has shown this relation to be true for several samples from the interior and underthrust sections of the Nankai accretionary prism. Furthermore, velocity-effective stress data from low velocity intervals in petroleum basins, where sonic velocities have been used to estimate overpressure (Bowers, 1994), suggest that this is a valid mechanism to produce low-impedance zones. However, quantitative data on the dependence of $V_{p}$ on $\sigma_{\text {eff }}$ in unlithified accretionary prism sediments are scarce, and to our knowledge, no data are available for the effect of the fracture systems and scaly fault fabric typical of these shallow accretionary prism thrust faults.

This study has been designed to experimentally test the hypothesis that the seismically imaged low-impedance zones are the product of fluid-pressure-induced reduction in velocity. This has been done by measuring $V_{p}$ vs. fluid pressure $\left(P_{f}\right)$ (or effective stress) under controlled confining pressure and fluid pressure, using whole round samples collected from the frontal thrust at Site 891 and the out-ofsequence thrust at Site 892 , as well as hanging wall and footwall material from both sites. The fundamental questions addressed by these experiments are:

1. Does velocity vary enough with effective stress fluctuations reasonable for the in situ conditions to produce the impedance contrasts suggested by the MCS modeling?

2. If so, what is the quantitative relationship between velocity and fluid pressure at the Oregon frontal thrust?

3. Does the velocity of fault zone scaly fabric fracture systems respond differently to elevated fluid pressure than the less fractured (but still poorly lithified) sediments of the hanging and foot walls?

4. How much volume/porosity change is associated with the velocity reduction with increasing $P_{f}$ ?

By answering these questions, we link inferences drawn from the MCS data to the physical response of the actual fault zone sediments. We use the experimental data to calibrate the fault zone reflection at Site 891 , estimating the actual present-day fluid pressure at that location on the frontal thrust. By generating curves of velocity vs. fluid pressure ratio, we are able to roughly correlate the reflection amplitude to a particular range of overpressures.The combination of experimental data with synthetic seismic reflection modeling is a new approach to fluid pressure estimation in an active fault zone. This exercise has significance for understanding the stress conditions accompanying accretion in this prism and the conditions for fluid flow, and also as an example of the potential for applying this technique to other similarly reflective faults, such as the Northern Barbados Ridge décollement.

Finally, we present preliminary results addressing the question of the magnitude of porosity change accompanying velocity reduction with effective stress. Most previous workers have equated elevated fault zone fluid pressure to elevated fluid content (i.e., enhanced porosity) and permeability. For example, in the case of the Barbados décollement zone, the inferred anomalously low velocity in the fault zone has been used to calculate a porosity enhancement of $14 \%$ (Westbrook, 1991) relative to the walls. However, in contrast to the relatively well-defined velocity-porosity curves during compaction (Hamilton, 1978), little data are available concerning the relationship of velocity to porosity during unloading due to the development of overpressure. Because of the strong dependence of compressibility on lithology, porosity rebound as a function of effective stress is also lithologically dependent. Thus, data relating velocity to porosity during unloading are needed to evaluate the degree to which enhanced hydrologic properties (porosity and permeability) can be inferred from pore pressure-induced velocity reduction.

\section{Oregon Accretionary Margin}

The Oregon accretionary margin (Fig. 1), where the Juan de Fuca plate subducts beneath North America, is characterized by a thick clastic trench-fill sequence overlying pelagic and hemipelagic abyssal plain deposits (Kulm et al., 1973; Westbrook, Carson, Musgrave, et al., 1994). MCS data show that, in the region of interest here, approximately $2 \mathrm{~km}$ of the sediment section is being accreted to the margin along thrust faults that root into a décollement. Fault-plane reflections are prominent in the MCS data from the décollement, frontal thrust, protothrusts, and out-of-sequence thrusts (MacKay et al., 1992; Cochrane et al., 1994), and these fault reflections (Fig. 2) are commonly discontinuous, high-amplitude reversed-polarity reflections, similar to those reported from other prisms.

During Ocean Drilling Program (ODP) Leg 146, two of these thrusts were penetrated and sampled. The main frontal thrust and an internal, or "out-of-sequence," thrust, intersected by Sites 891 and 892 , respectively, are both known from seismic data and submersible observations to be tectonically active and venting fluids (J.C. Moore et al., 1990; Moore et al., 1991). Both of these faults are prominent reflectors in the MCS profiles. The frontal thrust reflector at Site 891 is part of an extensive, discontinuous system of strike-parallel bands of high-amplitude reversed polarity reflectors (Moore et al., in press).

Hole $891 \mathrm{~B}$ was drilled and cored $472 \mathrm{~m}$ into the toe of the prism, penetrating clayey silts and fine to medium sands, all younger than middle Pleistocene (Westbrook, Carson, Musgrave, et al., 1994). The presence of thermogenic higher hydrocarbons and other geochemical anomalies in the pore water attests to active fluid advection between 200 and 440 mbsf at this Site. We obtained samples of splays of the main frontal thrust at Site 891, at depths of 367 and 440 meters below the seafloor (mbsf), as well as several wall-rock samples. These faults were identified primarily through mesoscopic (core-scale) textural features in the cores, exhibiting a range of structural features, including varying degrees of development of shear fractures, disrupted bedding and broken formation, deformation bands (Karig and Lundberg, 1990), and scaly fabric, defined as a submillimeter-scale network of anastomosing polished subparallel fractures (Lundberg and Moore, 1986). In the case of the two major splays at 367 and 440 mbsf, these structural fabrics also correlate to log and physical properties identification of structural discontinuities. At 367 mbsf, the fault was primarily characterized in the core by disrupted bedding and incipient scaly fabric, whereas the splay at 440 mbsf was identified primarily by the presence of deformation bands; scaly fabrics were not apparent. In contrast to the faults, wall-rock intervals are characterized by poorly lithified silts and silty clays, exhibiting bedding plane fissility 


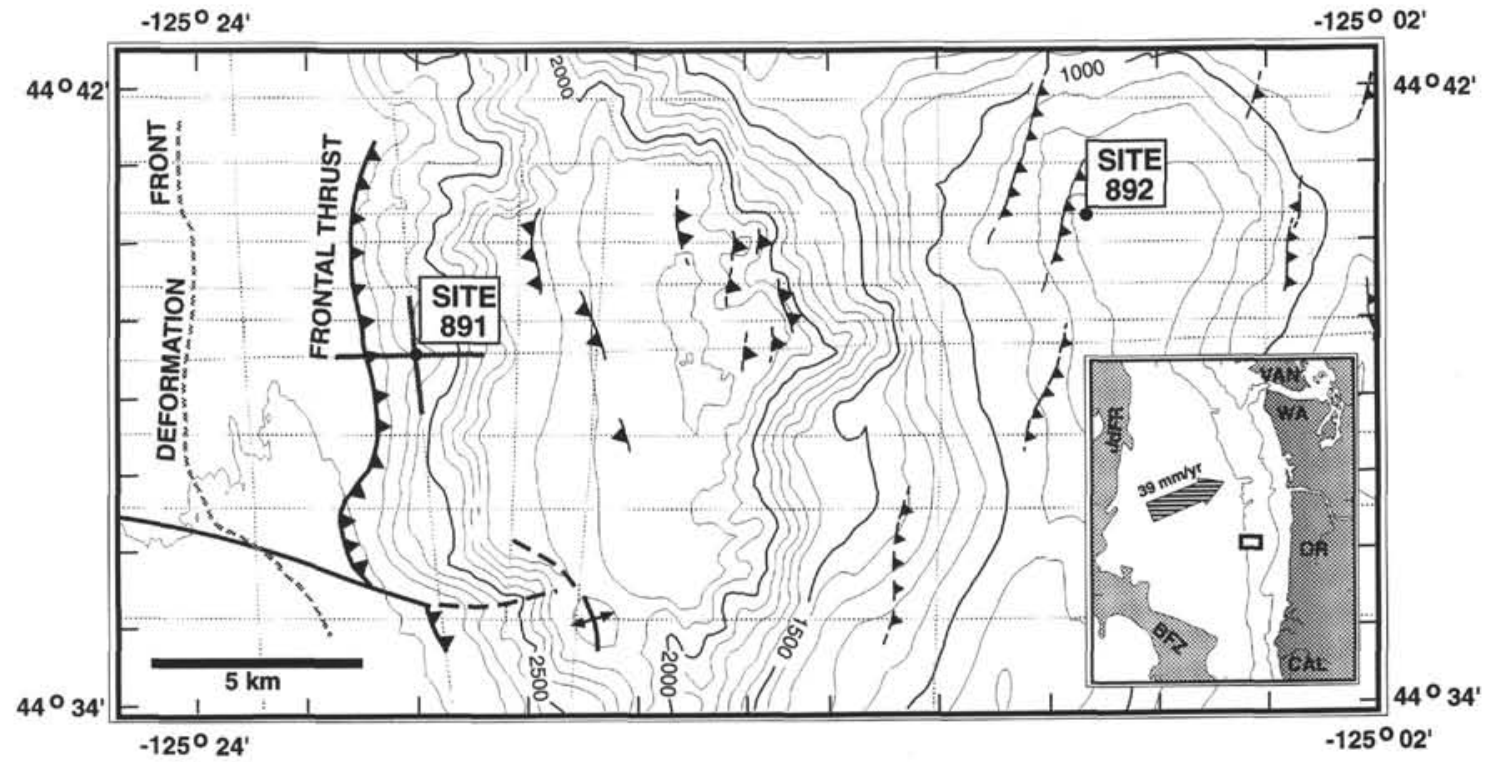

Figure 1. Bathymetry, multichannel seismic coverage (stippled lines), structural interpretation, and location of Sites 891 and 892 on the Oregon continental margin (see inset for location of study area). Bold lines crossing at Site 891 indicate portions of MCS Lines 5 and 41 shown in Figure 2. JdFR = Juan de Fuca Ridge, $\mathrm{BFZ}=$ Blanco Fracture Zone.

\section{Line 5}

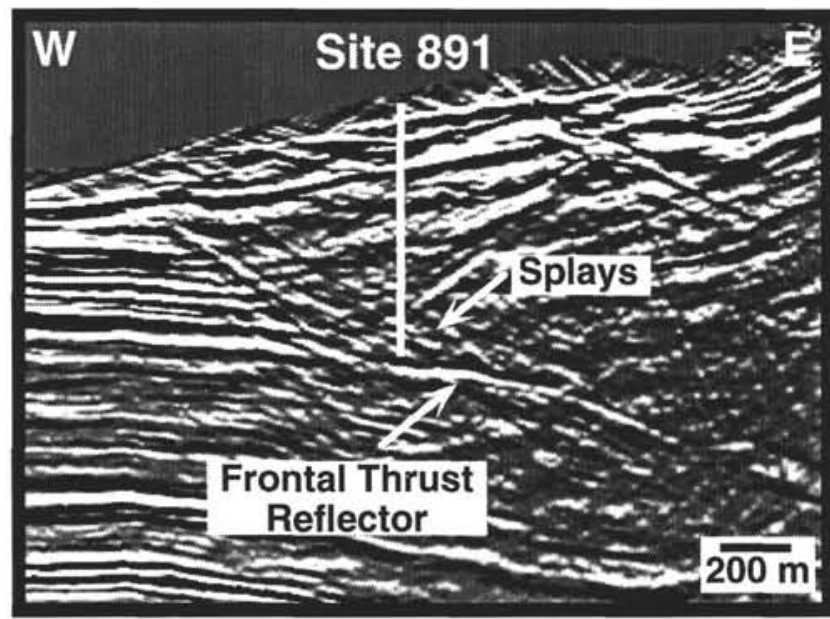

Line 41

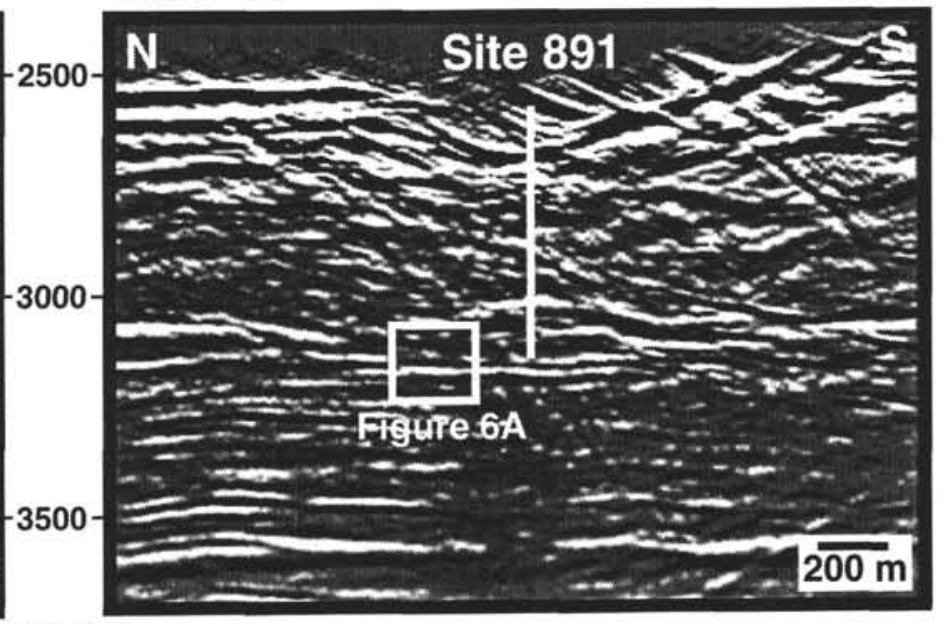

Depth (m)

Figure 2. Mutually perpendicular, migrated multichannel depth sections from the Site 891 region, Oregon accretionary prism. Lines 5 and 41 are perpendicular and parallel to strike of frontal thrust, respectively, and cross at the location of Site 891. Reflections from the various splays of the frontal thrust are prominent. The location of the enlarged fault-plane reflections shown in Figure 6A is indicated.

and open fractures of apparent tectonic origin, but little or no evidence of localized shear surfaces (Westbrook, Carson, Musgrave, et al., 1994). Fault zone and wall rock alike share the common characteristic of poor to absent cementation and lithification.

At Site 892 , coring to a total depth of 176.5 mbsf was accomplished in Holes 892A and 892D and revealed fairly uniform sediments of silty clay to clayey silt which are pervasively stratally disrupted. We collected samples at this Site from the out-of-sequence thrust (at $109 \mathrm{mbsf}$ in Hole 892A) and the hanging wall and footwall blocks. Hole 892A intersected the top of the out-of-sequence thrust zone at $104 \mathrm{mbsf}$; this thrust also forms a prominent reflector like the ones at Site 891 , but the reflection polarity and signature is more am- biguous than the frontal thrust, and does not lend itself to the detailed waveform analysis presented below for the frontal thrust reflector. Evidence for active fluid flow in the fault at Site 892 includes geochemical anomalies, excursions in the temperature-depth profile, and the measurement of superhydrostatic fluid pressures in a packer test of the fault zone (Westbrook, Carson, Musgrave, et al., 1994). The major fault, represented here by Sample 892A-10X-7, 87-103 $\mathrm{cm}$, was recognized by the presence of intensely disrupted bedding, mélange, and scaly fabric, forming coherent core in some intervals and breaking into small (subcentimeter) angular fragments in others. The fault zone identified in the cores corresponds to the calculated depth to the planar reflector. Microstructural analysis of samples 
from this fault zone confirm the presence of ubiquitous kink-like and shear-zone-like deformation bands, as well as cataclastic deformation (Teas et al., this volume). Sediments of the wall rock, represented here by Sample 146-892A-18X-2, 0-22 cm, from the footwall, consist of poorly lithified broken formation, with little or no scaly fracture fabric evident. However, unlike at Site 891, none of the sediments from this site totally lack shear fabrics.

\section{EXPERIMENTAL METHODS}

We measured ultrasonic $V_{p}$ under constant confining pressure and varying fluid-pressure conditions. Whole rounds were bandsawtrimmed into approximately cubic subsamples $25 \mathrm{~mm}$ on a side, and were then loaded into a confining vessel fitted with ports allowing pore pressure control (Fig. 3). Seawater saturation was maintained throughout the sample preparation process to minimize induced cracking and other disturbance of the samples. $P$-wave velocity transducers are mounted in the sample end platens so as to measure velocity in a vertical path. Internal fluid pressure was controlled by means of a pressure generator ported to the sample, and the pore fluid (seawater) was isolated from the confining medium by a flexible latex membrane over the sample and end platens. The samples were then subjected to the first increment of isotropic confining pressure $\left(\sigma_{c}\right)$, somewhat less than the calculated wet bulk overburden stress resulting from their depth below the seafloor and the density of the overlying sediments. We believe isotropic stresses are a reasonable simplification of in situ conditions for this study since vertical $V_{p}$ is primarily a function of vertical (overburden) stress (Bourbié et al., 1987), and we have no basis for estimating the magnitudes of in situ horizontal stresses.

We calculated $V_{p}$ from pulse-transmission time measurements following methods adapted from Christensen (1985). We used 400kHz ultrasonic transducers, excited by a 400 -ns, 380-volt pulse pro-

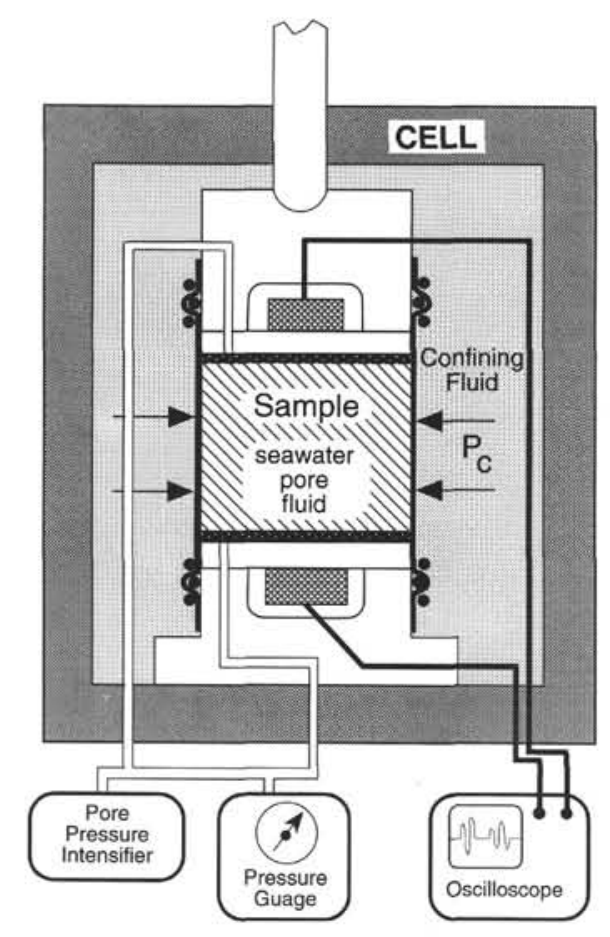

Figure 3. Block diagram of laboratory apparatus for applying independent fluid and confining pressures and measurement of $P$-wave traveltimes (not to scale). $P_{c}=$ confining pressure. duced by a Panametrics 5055PR pulser/receiver. Traveltime was measured on a digital oscilloscope. Path length was initially measured with a dial caliper, then monitored by means of an LVDT coupled to the top (nonfixed) end platen. The velocity was measured parallel to the vertical core axis to mimic vertical-incidence seismic reflection. Error introduced by the frequency difference between ultrasonic and seismic sources is considered negligible (Bourbié et al, 1987). The absolute error of calculated velocity for the samples is within $2 \%$, but relative velocity changes within a given sample are accurate to $\sim 1 \%$. All measurements were made at room temperature $\left(20^{\circ} \mathrm{C}\right)$, which is within $10^{\circ} \mathrm{C}$ of in situ values (Westbrook, Carson, Musgrave, et al., 1994), so no temperature corrections were applied.

Sample pore pressure was controlled independently of $\sigma_{c^{*}}$. For each sample, confining pressure was applied and $P_{f}$ was simultaneously brought up to $25 \%$ of $\sigma_{c}$, (equivalent to subhydrostatic conditions), then $P_{f}$ was increased up to $\sigma_{c}$ (zero effective stress) in increments of $\sim 5 \%$ of $\sigma_{c}$, and a $V_{p}$ measurement was taken at each increment. After a series of measurements were completed, $P_{c}$ was raised to the next increment, the sample was allowed to equilibrate, and the cycle of $P_{f}$ steps and $V_{p}$ measurements was repeated. In this way, individual samples could be used to evaluate velocity variation with effective stress under a wide range of stress conditions, including $\sigma_{\text {eff }}$ greater than in situ values. All samples were tested using these procedures. Note that, during the two lower pressure tests on Sample 146-891B-30X-2, 13-26 cm, insufficient time was allowed for the sample to fully equilibrate to the changing stress at each fluid pressure increment, resulting in the convex upward shape of these two curves. After this problem was identified, all subsequent tests were performed allowing for equilibration after fluid pressure conditions were changed before traveltime measurements were made.

\section{RESULTS}

\section{Velocity Measurements}

Results of $V_{p}$ measurements on the samples are shown (Figs. 4 and $5)$ as velocity as a function of $\lambda$, the fluid overpressure ratio $\left(P / \sigma_{c}\right)$ of Hubbert and Rubey (1959), to facilitate visualization of the effect of overpressure on velocity. Following Davis et al. (1983), we ignore pressure due to the overlying water column above the seafloor. We were able to carry out successful tests on coherent subsamples of the whole rounds for four samples from Site 891 and two from Site 892. All of our test samples were of clayey silt lithology, and were poorly to very poorly lithified. Samples 146-891B-55X-2, 74-85 cm, and $47 \mathrm{X}-2,92-100 \mathrm{~cm}$, are representative of two of the splays of the frontal thrust system (see Moore et al., this volume, for thrust-zone geometry). These two samples contain various structural fabrics, including shear-zone-type deformation bands (Maltman et al., 1993; see Teas et al., this volume, for examples of the microstructures in these samples), and weakly developed, subhorizontal scaly fabric. Samples 146-891B-30X-2, 13-26 cm, and 58X-1, 75-95 cm, are wall-rock material. They lack localized shear fabrics and are dominated by bedding-parallel compaction fabrics. In Site 892 samples, structural fabrics are much more pervasively developed, and it is more difficult to identify fault-rock/wall-rock distinctions. However, Sample 146$892 \mathrm{D}-10 \mathrm{X}-7,87-103 \mathrm{~cm}$, is from the zone of most intensely developed shear fabrics, including moderately well-developed scaly fabric, of the out-of-sequence thrust, and Sample 146-892A-18X-2, 0$22 \mathrm{~cm}$ is from a zone of less-intense shear fabrics in the foot wall of that fault zone, exhibiting spaced shear-zone-type deformation bands and weakly developed scaly fractures.

In all of the tested samples, regardless of structural fabric, velocity is dependent to varying degrees on effective stress and, therefore, on $\lambda$ (at constant $\sigma_{\mathrm{c}}$ ). Over the range from hydrostatic $P_{f}(\lambda=\sim 0.5$ ) to lithostatic $P_{f}(\lambda=1)$, velocity decreased by an amount ranging from 80 to $350 \mathrm{~m} / \mathrm{s}$, or $8 \%$ to $18 \%$, depending on the sample and on the ap- 

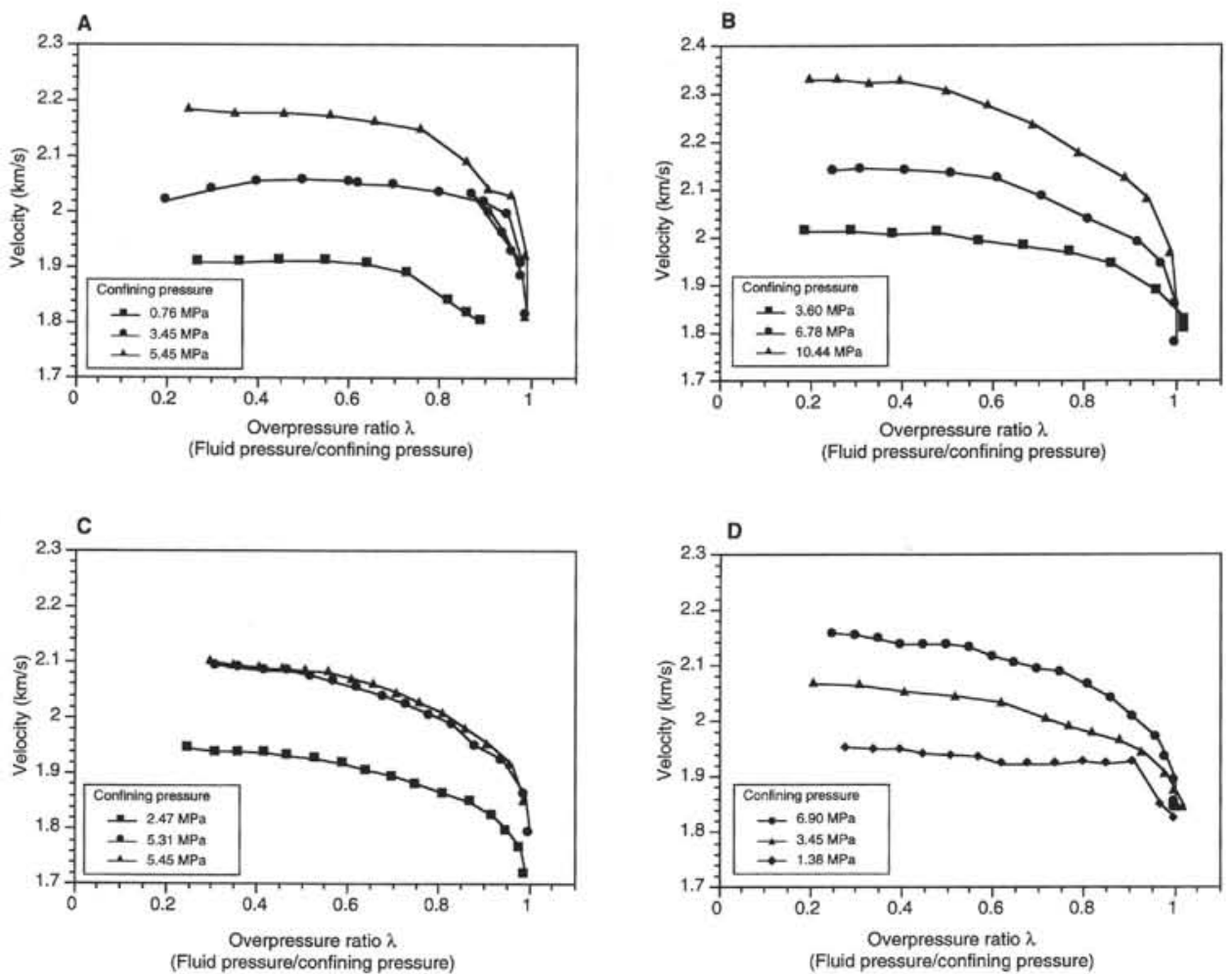

Figure 4. $P$-wave ultrasonic velocity vs. overpressure ratio $(\lambda)$ for Site 891 samples, measured at indicated confining pressures $\left(\sigma_{c}\right)$. A. Sample 146-891B-30X2, 13-26 cm, from the hanging wall block. B. Sample 146-891B-47X-2, 92-100 cm, from a minor fault zone. C. Sample 146-891B-55X-2, 74-85 cm, from the upper splay of the frontal thrust. D. Sample 146-891B-58X-1, 75-95 cm, from the relatively undeformed footwall of the upper splay of the frontal thrust.
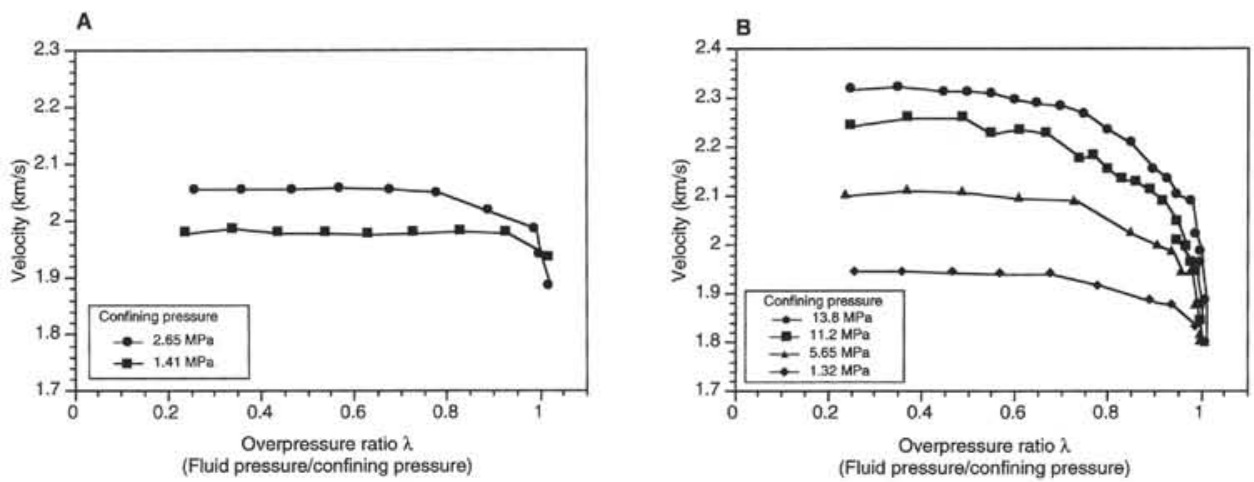

Figure 5. $P$-wave ultrasonic velocity vs. overpressure ratio $(\lambda)$ for Site 892 samples, measured at indicated confining pressures $\left(\sigma_{c}\right)$. A. Sample 146-892D-10X$7,87-103 \mathrm{~cm}$, from the out-of-sequence thrust. B. Sample 146-892D-18X-2, 0-22 cm, from the footwall of the out-of-sequence thrust.

plied confining stress. All the velocity vs. overpressure ratio curves in Figures 4 and 5 show the same general form: little variation under modest overpressures, then a steepening of the curves above $\lambda=0.7$ to 0.8 , and pronounced velocity decrease above $\lambda=\sim 0.9$. As expected, these results and the general curve shapes are in keeping with a wealth of published data for geologic materials from other settings (Bourbié et al., 1987). The curves reach near-stable velocities at lower effective stresses than materials tested in other published studies, probably due to the shallow burial of these samples and concomitant very low effective stresses they have experienced. Most or all rocks for which published data are available are much more lithified than those of the present study.

Curves from the three fault-rock samples (146-891B-55X-2, 74 $85 \mathrm{~cm}, 47 \mathrm{X}-2,92-100 \mathrm{~cm}$, and 892D-10X-7, 87-103 cm) differ little from those from the respective hanging-wall and footwall regions, when runs from similar confining pressures are compared, despite the presence of fault fabrics and different consolidation state. For example, compare the curves from Samples 146-891B-55X-2, 74-85 cm, and $58 \mathrm{X}-1,75-95 \mathrm{~cm}$, from the middle splay of the frontal thrust and its footwall, respectively. The fault zone is only a few tens of meters per second slower than the footwall, even at a substantially lower confining pressure (5.45 vs. $6.90 \mathrm{MPa}$ ). At Site 892, comparing Sample 146-892D-10X-7, 87-103 cm (fault zone), with Sample 146$892 \mathrm{~A}-18 \mathrm{X}-2,0-22 \mathrm{~cm}$ (footwall), shows that the fault zone is of slightly higher velocity than the footwall at similar effective stress (1.32 vs. 1.41 MPa). Sample 146-891B-30X-2, 13-26 cm, does appear to have an inherently faster velocity (of about $100 \mathrm{~m} / \mathrm{s}$ ) than Samples $55 \mathrm{X}-2,74-86 \mathrm{~cm}$, or $47 \mathrm{X}-2,92-100 \mathrm{~cm}$, at similar confin- 
ing pressure, but since its in situ confining pressure is much lower (it is from 237 mbsf, whereas $47 \mathrm{X}-2,92-100 \mathrm{~cm}$, is from $367 \mathrm{mbsf}$ and $55 \mathrm{X}-2,74-86 \mathrm{~cm}$, is from $440 \mathrm{mbsf}$ ), the in situ velocity would be less than the deeper fault zone samples (assuming similar fluid pressure ratio).

For the purposes of this study, the relative stress-induced variations in velocity for each sample are more meaningful than velocity differences at the same $\lambda$ between samples because of the uncertain compaction history of the samples and different confining pressures during testing. However, it is clear that velocity differences between samples at similar $\sigma_{\text {eff }}$ are within the range of normal lithologic variation. The fact that fault samples do not exhibit unusual lithology or cementation (Westbrook, Carson, Musgrave, et al., 1994; Teas et al., this volume), and that the presence or absence of fault fabrics does not appear to have a prominent effect on the velocity vs. effective stress relationship, suggests that the impedance anomaly accompanying the fault plane in the seismic data does not result from an inherent velocity or density anomaly in the fault zone independent of stress and fluid pressure. Furthermore, the similarity of the curves from fault and wall alike indicates that the fault zone fracture fabrics do not respond in a substantially different way to pore pressure variations than do the adjacent sediments lacking fault fabric.

\section{Modeling of Frontal Thrust Reflector}

The goal of collecting this velocity data has been to evaluate the contribution of fluid-pressure-induced velocity reduction to the generation of the anomalous seismic reflections in this and other prisms. The frontal thrust reflector at Site 891 is in one of these high-amplitude, negative-polarity zones. The reflection at Site 892 from the outof-sequence thrust is also of high amplitude, but the polarity and waveform are not clear, owing to interference from other arrivals and its discontinuous nature. Therefore, we have chosen Site 891 for calibration of the reflection to fluid pressure, despite the availability of borehole hydrologic test data only at Site 892 . Regrettably, this means that the results of this exercise cannot be compared to direct measurements of pore pressure made during or after the leg. Detailed analysis of the seismic reflection data by Moore et al. (this volume) indicates that at least three splays of the frontal thrust have developed in the Site 891 vicinity. We have chosen to model the lowest splay, which is the one that forms the most prominent seismic reflector.

To determine the velocity and density structure producing the frontal thrust reflection in the vicinity of Site 891 , we have performed waveform and limited relative amplitude modeling of the frontal thrust reflection in the 1989 MCS survey. The goals of the modeling were to determine (1) whether the fault is a simple negative impedance boundary or a compound reflector of discrete thickness, with sharp impedance contrasts at both top and bottom, and (2) if it is a discrete layer, what is its thickness and impedance relative to the wall rocks.

We modeled traces extracted from strike-parallel MCS Line 41 (Fig. 6A). To avoid distortion of the waveform, we used only a sixfold near-trace stack of each common midpoint gather for modeling purposes. The proximity of relatively high-amplitude nearby reflectors necessitated migration of this stack to improve imaging of the fault-plane reflector; however, before-and-after comparison of the seafloor reflection indicates that waveform distortion due to migration is minimal. The wavelet traces shown in Figure $6 \mathrm{~A}$ are from the frontal thrust reflection (flattened on $4.0 \mathrm{~s}$ for ease of inspection). Shot traces 447-452, 100-200 m north of Hole 891B, were chosen for modeling because of poor imaging at the location of that hole (shot trace 456). For modeling purposes, we have assumed that density variations are small compared to velocity, given the homogeneous lithology at this site, and that velocity dominates the
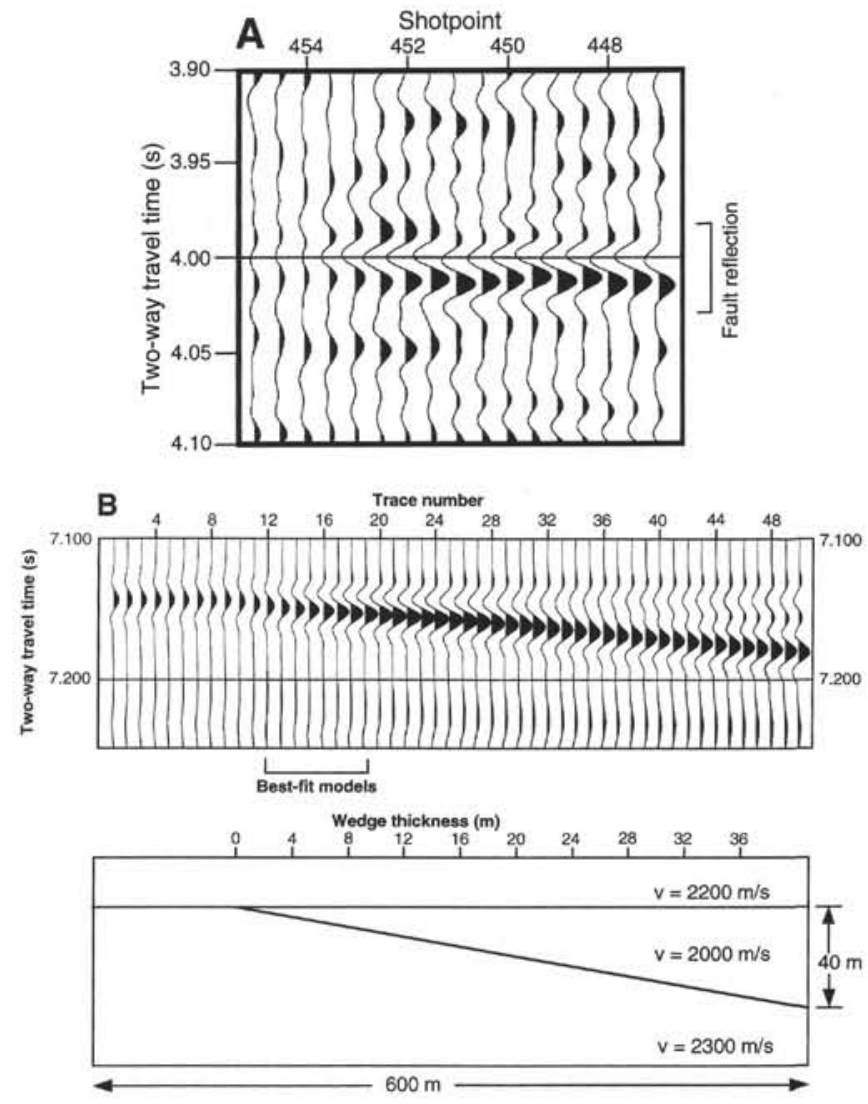

Figure 6. A. Near-trace stack of a portion of the frontal thrust reflection in the Site 891 vicinity extracted from Line 41 , with frontal thrust reflection flattened on $4.0 \mathrm{~s}$. Note the asymmetry of the frontal thrust wavelet. The left-toright orientation of the traces has been reversed in the display from that of Figure 2. B. Synthetic traces of best-fit wedge model, used to evaluate thickness and impedance contrasts of frontal thrust reflection. This model has a wedge of low-velocity material, representing the fault zone, sandwiched between higher velocity "hanging wall" and "footwall." The waveform is fit best by this model in which the hanging wall is of lower velocity than the footwall. Density varies in the model according to the Gardner (1974) equation. The duration of the fault zone wavelet in Figure 6A is matched by the synthetic traces through the wedge where it is 2 to $9 \mathrm{~m}$ thick (traces 12-19).

impedance contrast. The source wavelet used to model the fault reflector was obtained by stacking 500 seafloor reflection traces, using near traces from individual shots. This source wavelet is nearly symmetrical, exhibiting a negative-positive-negative sequence of deflections (i.e., it is a normal marine source wavelet). The actual frontal thrust waveform (Fig. 6A) is variable but generally asymmetric, exhibiting a sequence of a positive lobe, a large negative lobe, an approximately equal-amplitude positive lobe, and a small negative lobe.

In the first part of the modeling, we generated wedge models (Fig. $6 \mathrm{~B})$ to determine whether the reflector is one boundary or two and, if two, the thickness of the anomalous zone. All models that have a single impedance contrast boundary fail to model the asymmetry of the fault reflector. An example is the left side of Figure 6B, where a symmetric positive-polarity reflection is produced by a single boundary. Given the symmetric source signal input, the asymmetry observed in the data can only be produced by a compound reflection created by constructive interference (tuning effects). On the far right side of the 
wedge model, where there are two boundaries separated by $40 \mathrm{~m}$, two separate reflections are distinguishable; this also generally fails to model the fault reflections. The predominant fault reflector must therefore result from two boundaries spaced $<1$ wavelength apart.

The only wedge models that match the features of the fault reflector are those in which the wedge is of lesser velocity than either the hanging wall or footwall and in which the footwall is of greater velocity than the hanging wall, as in Figure 6B. We estimate the thickness of the low-velocity zone by comparing the duration of the model pulses (in milliseconds) to the data traces. Note in Figure 6B that as the wedge thickens, the compound reflection lengthens in duration.The fault-reflector wavelet in the field data averages $40 \pm 3 \mathrm{~ms}$ long (measured from the zero crossing at the top of the first positive to the bottom of the second positive). The wedge thickness producing a wavelet that matches this duration is between 2 and $9 \mathrm{~m}$ (traces 12 19 in the wedge model).

Based on the wedge models, we do not know the magnitude of the impedance contrast for this reflection. Because the amplitude is not scaled to the data, only the sign of each impedance contrast is important in the wedge models. Wavelet amplitude varies with the magnitude of the impedance contrasts across the boundaries. Unfortunately, the true reflection amplitude in the near-trace stack is unknown due to instrumental factors and transmission effects such as waveform interference, focusing, absorption, and spreading. We attempted to partially circumvent this problem by calibrating the amplitude of the frontal thrust reflector to the seafloor reflection amplitude, using the seafloor reflection coefficient, calculated from the ratio of the amplitude of the seafloor and the seafloor multiple (White, 1977). This technique eliminates instrumental uncertainty, and transmission effects are likely to be minor given the shallow subbottom reflection depth. The seafloor reflection coefficient calculated using this technique is 0.250 , averaged over 50 measurements of seafloor and first multiple amplitude, and the average reflection coefficient of the frontal thrust is 0.049 , or $20 \%$ that of the seafloor.

A series of one-dimensional synthetic traces (Fig. 7) model the relative amplitude of the seafloor and the frontal thrust. We matched the seafloor to the calculated reflection coefficient of 0.250 and var- ied the velocity in the 6-m-thick layer representing the fault. We assigned velocities of $2200 \mathrm{~m} / \mathrm{s}$ above, on the basis of a vertical seismic profile (Westbrook, Carson, Musgrave, et al., 1994), and $2300 \mathrm{~m} / \mathrm{s}$ below the fault layer to conform to the waveform model. Within the fault layer, the velocity varies from $1800 \mathrm{~m} / \mathrm{s}$ to $2200 \mathrm{~m} / \mathrm{s}$ across Figure $7 \mathrm{~A}$. A fault zone amplitude that is $20 \%$ of that of the seafloor is produced by a velocity $\sim 150 \mathrm{~m} / \mathrm{s}$ slower than the wall rocks. Given potential error caused by uncertainties discussed above, a reasonable range for the true amplitude is 0.5 to 2 times this value (one-tenth to two-fifths of seafloor amplitude), which is produced by velocity contrasts from 100 to $300 \mathrm{~m} / \mathrm{s}$.

To summarize the results of this modeling, the waveform and relative amplitude models suggest that the frontal thrust reflector in the vicinity of Site 891 is the result of a discrete layer, 2-9 m thick, with sharp top and bottom boundaries, which has a velocity $100-300 \mathrm{~m} / \mathrm{s}$ lower than the walls.

\section{ESTIMATING FLUID PRESSURE}

With this velocity model for the frontal thrust, we can combine the experimental data with the model results to estimate fluid pressure in the fault zone, assuming that all of the impedance anomaly can be attributed to the mechanism of fluid-pressure-induced velocity reduction. This assumption may or may not be valid. For example, the presence of free gas in the fault zone could also substantially reduce acoustic velocity (Domenico, 1976). However, in this case, the reversed polarity reflections from the Oregon frontal thrust at Site 891 occur at relatively shallow depth below the seafloor, placing them within the gas hydrate stability zone (Hyndman et al., 1992), where free gas is not expected to be present. Another possibility is velocity variation due to changes in lithology or cementation in the fault zone, also unlikely in this case since the fault cuts across bedding and exhibits neither unusual fault lithology or preferred cementation in the cores.

One additional difficulty is that the modeled lower splay reflector of the frontal thrust is just below the maximum drilled depth at Site

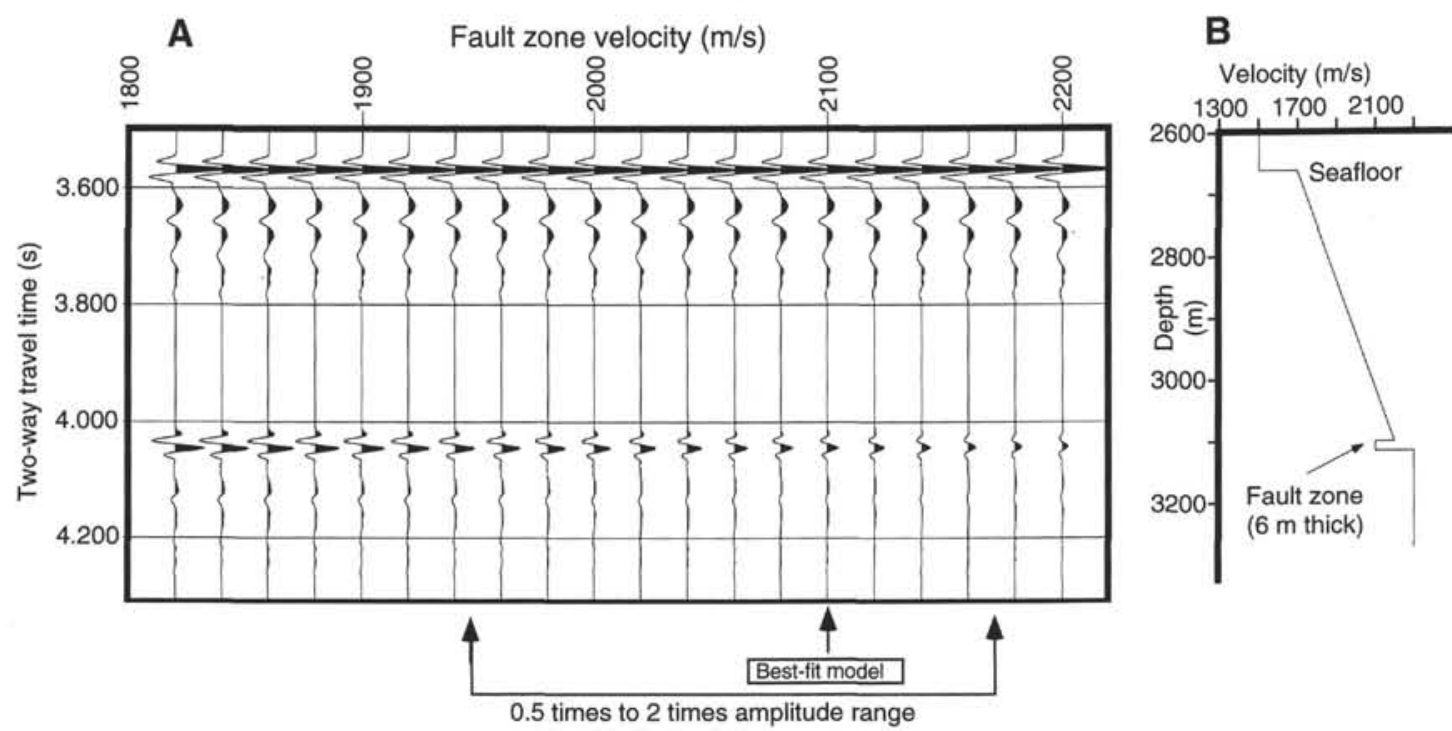

Figure 7. A. A series of model traces showing relative amplitude of seafloor and frontal thrust reflectors for different velocity contrasts between fault zone and walls. The seafloor was assigned velocity and density to give it the calculated reflection coefficient of 0.250 (see text for discussion). The thickness of the fault zone $(6 \mathrm{~m})$ is taken from the wedge model of Figure $6 \mathrm{~B}$. Hanging wall and footwall velocities are set using vertical seismic profile data and to match the waveform data. The velocity in this zone varies from left to right across the model space from 1800 to $2200 \mathrm{~m} / \mathrm{s}$. Best fit is $2100 \mathrm{~m} / \mathrm{s}$ fault zone, giving the fault zone an amplitude of $20 \%$ of that of the seafloor, with a likely range of 2250 to $1950 \mathrm{~m} / \mathrm{s}$, or $10 \%$ to $40 \%$ of seafloor amplitude, given uncertainty. B. Velocity-depth profile of best-fit model for frontal thrust. 
891. Unfortunately, only the upper and middle splays were sampled by coring and available for testing purposes. However, based on the homogeneity of the sediments, the uniform behavior of different samples under varying fluid pressure ratios, and the small ( $75 \mathrm{~m})$ separation of the middle and lower splays, we are confident that we can use the experimental data from these splays in conjunction with the seismic modeling results to estimate the fluid pressure conditions. We have chosen single velocity vs. $\lambda$ curves for each sample, at confining pressures nearest to (but below) those calculated from burial depth, and combined them into one graph in Figure 8. Note that for Sample 146-891B-30X-2, 13-26 cm, we show data from a higher $\sigma_{c}$ than that corresponding to its burial depth because of experimental difficulties during a lower pressure test (see "Experimental Methods" section, this chapter).

By using Sample 146-891B-55X-2, 74-85 cm from the upper thrust splay, the requisite 100 to $300 \mathrm{~m} / \mathrm{s}$ of velocity reduction translates to an overpressure range of $\lambda=0.86$ to 0.99 ; the best fit $(150 \mathrm{~m} /$ s) reduction suggests $\lambda=0.92$ (Fig. 8). Similarly, Sample 146-891B$47 \mathrm{X}-2,92-100 \mathrm{~cm}$, from another apparent thrust splay, would require $\lambda=0.92$ to 0.99. For comparison, wall-rock Samples 146-891B-30X$2,13-26 \mathrm{~cm}$, and $58 X-1,75-95 \mathrm{~cm}$, require $\lambda=0.86$ to 0.97 and $\lambda=$ 0.86 to 0.98 , respectively. All of these samples produce consistent values, so we conclude that fluid pressure $>85 \%$ of lithostatic, confined to the fault zone, is probably required to explain the anomalously low impedance in the frontal thrust reflection at Site 891, and fluid pressure $>95 \%$ of lithostatic is not unreasonable. Significantly, superlithostatic fluid pressure is not required.

\section{Mechanism of Velocity Reduction}

In previous work on such negative-polarity fault-plane reflectors, most authors have equated high fluid pressures with elevated porosity, fluid content, fluid flow, and/or permeability of a dilated faultzone fracture fabric (e.g., Bangs and Westbrook, 1991; Moore et al., 1991; Shipley et al., 1994). However, significant fracture opening implies the occurrence of natural hydrofracture (Sibson, 1981), requiring lithostatic fluid pressure under thrust-faulting stress conditions. The exercise presented above suggests that superlithostatic fluid pressure is not required to create these reflections. If so, this

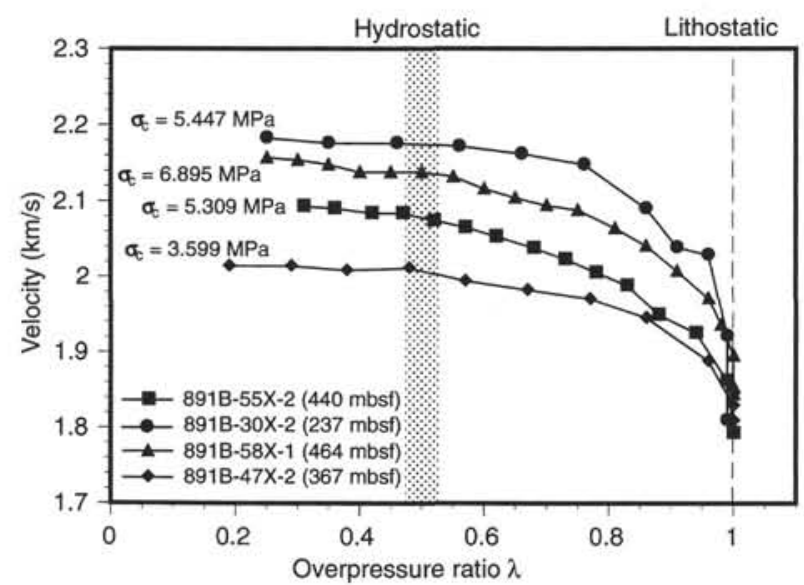

Figure 8 . Selected $P$-wave ultrasonic velocity vs. overpressure ratio $(\lambda)$ curves for all Site 891 samples. These are the four curves from Figure 4A-D, for which $\sigma_{c}$ is nearest to calculated values generated by overburden. These four curves were used to estimate the in situ fluid pressure necessary to cause the velocity reductions indicated by the waveform and amplitude modeling of the frontal thrust zone. conclusion begs the question: what magnitude of porosity enhancement is likely during unloading through a sublithostatic pore pressure range? Reliable sample volume change data were only acquired during one of the tests, fortunately on Sample 146-891B-55X-2, 74-85 $\mathrm{cm}$, a thrust splay sample. Volume measurements made during this test show that sample volume increased by $<1 \%$ as $\lambda$ increased from 0.30 to 0.93 (at $\sigma_{c}=5.31 \mathrm{MPa}$ ), then changed by $\sim 3 \%$ more between $\lambda$ of 0.93 and 1.0. This magnitude of rebound is consistent with data from the consolidation curves of Moran et al. (this volume) and results from Nankai prism samples derived from Sites 582 and 808 (Karig, 1993), but is much less than the 10\%-13\% rebound reported for the smectite-rich Barbados décollement zone from Site 671 (Taylor and Leonard, 1990). These large differences in porosity rebound are probably attributable to different compressibilities of the lithologies. Thus, at all effective stresses such that $\lambda<0.93$, porosity changes are nearly insignificant, despite relatively large variations in velocity. It is possible then, given the minimum requisite overpressure of $\lambda=0.86$ indicated here, that the concomitant velocity reduction occurs with little volumetric dilation.

It is interesting to compare these results with the permeability vs. effective stress data of Brown (this volume), who reports an acceleration in the rate of increase in permeability with decreasing effective stress, where effective stress is below approximately $100 \mathrm{kPa}$, or $\lambda \geq$ 0.986 (at the depth of the frontal thrust). Since a large cumulative velocity reduction occurs in conditions where $\lambda<0.98$, the impedance anomalies may not necessarily image the conditions conducive to high porosity/permeability. On the other hand, $\lambda \geq 0.98$ confined to the fault zone would certainly also produce a large impedance contrast. Clearly, future work needs to couple measurement of both velocity and permeability together as functions of effective stress on the same sample in order to test this possibility.

Rather than resulting from substantial variations in porosity in the overpressured zones, velocity reduction may result in part from changes in rigidity and bulk modulus of the sediment framework with reduced effective stress. That is, the grain-to-grain (or fracture-surface) contact strength varies with effective stress. Lacking $S$-wave velocity data, we cannot provide evidence supporting this mecha-

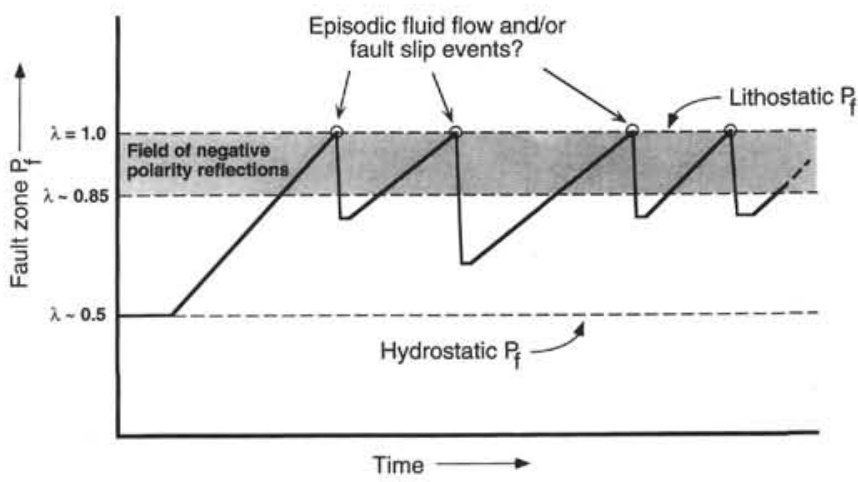

Figure 9. Proposed cycle of fluid pressure in the frontal thrust vs. time (after Sibson, 1990). As fluid pressure rises toward lithostatic, it passes into the field of negative polarity reflections. Our data indicate that this threshold is crossed at approximately $\lambda=0.85$ at Site 891 . Fault slip, hydrofracture, and or episodic flow possibly only occur at or near lithostatic fluid pressure, causing rapid draining and reduction of pressure to some unknown, perhaps still greater than hydrostatic, value. Since fault reflections are discontinuous, pressure probably drops below the threshold for reflectivity at least some of the time. In this conceptualization, high negative-polarity reflectivity indicates elevated fluid pressure, but does not necessarily imply enhanced flow or porosity, as supported by velocity vs. overpressure data presented here. 
nism, but it is well established that elastic moduli vary with effective stress (Bourbié et al., 1987). Dependence of rigidity on effective stress would be especially likely in these uncemented and weakly lithified sediments.

Brown et al. (1994) have argued that superlithostatic pore pressure and hydrofracture are almost certainly transient conditions. We propose (Fig. 9) that the fault plane reflections may image intermediate stages in an episodic fault valving cycle, as proposed by Sibson (1990). In this scenario, pore pressure builds up until it reaches lithostatic (for low-strength material), then hydrofracture and/or shear failure occurs and permeability increases transiently. It is during this phase that episodic fluid flow is likely. Pore pressure is thereby reduced to some lower (but probably still greater than hydrostatic) value, and the cycle continues. We envision the fault plane reflections as images of the fault zone during either this phase of rising pore pressure or the transient failure/flow phase. We emphasize that the absolute or relative time scales for these processes and phases are unknown. In any case, as pore pressure rises toward lithostatic from some lower value, it passes through the $\lambda=0.85$ threshold in this case (it could be some other value in other examples), and develops the characteristic negative-polarity reflection signature. The patchy nature of the negative-polarity reflections suggests that overpressure must be below this range at some times and locations. We speculate that this reflection might become brighter as lithostatic fluid pressure is approached and reached, then disappear after the failure/hydrofracture event. Thus, if the shape of this overpressure/time curve is broadly correct, the negative polarity reflections may represent either the transient failure event with attendant hydraulic dilation, or the (probably) longer-duration interval of pore pressure buildup.

\section{SUMMARY AND CONCLUSIONS}

Laboratory measurements of $V_{p}$ as a function of pore pressure and confining pressure in samples taken from Sites 891 and 892 of the Oregon accretionary prism demonstrate that velocity varies by as much as $15 \%$, or about $300 \mathrm{~m} / \mathrm{s}$, due to reasonable pore pressure variations, given in situ stress conditions. Furthermore, we find that the velocityeffective stress functions are similar for samples exhibiting strong faulting-related shear fabrics and those with little or no shear fabric. These first-order results confirm that the often-cited reduction of acoustic impedance by anomalous fluid pressure is a viable hypothesis to explain high-amplitude negative polarity fault-zone reflections.

Combining the experimentally derived velocity vs. fluid pressure ratio curves with synthetic models of the seismic reflection signature of the frontal thrust at Site 891, we estimate the pore pressure necessary to produce the reflections. Waveform and relative amplitude modeling of the frontal thrust reflection shows that it is produced by a zone $2-9 \mathrm{~m}$ thick that has a velocity 100 to $300 \mathrm{~m} / \mathrm{s}$ slower than the wall rocks. The experimental data from the Site 891 samples show that this velocity reduction can be generated with fluid pressure of $86 \%$ to $99 \%$ of lithostatic pressure for the in situ confining pressure. The best fit value is $\sim 92 \%$. Some of the velocity anomaly could be the result of undercompaction and associated unusually high porosity in the fault; this would almost certainly also derive from a history of overpressure (Fertl, 1976), and would also require $\lambda>0.90$ (Moore et al., this volume).

The fact that the fault zone generates a strong reflection, yet fault zone and wall rock alike exhibit similar $V_{p}$ vs. $\lambda$ functions, suggests that significant fluid-pressure gradients must exist across the fault zone boundaries to make the impedance contrast. That is, the anomalously high fluid pressure must exist only in a restricted thin layer, giving it low impedance. This is in contrast to a scenario in which there is a broad area of elevated fluid pressure, but in which fault fabric has a different velocity response to that fluid pressure than surrounding sediments. The presence and maintenance of these gradients indicates that permeability perpendicular to the fault zone margins must be low.

Superlithostatic fluid pressure and resulting hydrofracture is not required by the data and models to explain the reflection signature. The question of the physical mechanism producing the low-impedance zone remains open; however, the volume change data for the frontal thrust sample presented here suggests that significant dilation of the fault fabric may not necessarily accompany velocity reduction, as has previously been assumed. Confirmation and quantification of this observation awaits further study. Comparison of these results with those of Brown (this volume) suggests that velocity reduction sufficient to produce the frontal thrust reflection can occur with or without accompanying large permeability enhancement.

To our knowledge, this study calibrates fluid-pressure-induced fault-plane reflections for the first time in any geologic setting. In petroleum production, velocity has long been used empirically to estimate overpressure (Fertl, 1976; Bowers, 1994); our work extends this application to thin low-velocity zones only resolvable by modeling of multichannel seismic reflection data. Interestingly, in a very different geologic setting, Jones and Nur (1984) concluded that elevated fluid pressure was responsible for the strong reflectivity of deep crustal shear zones in the COCORP Wind River profile, based on measurements of velocity vs. effective stress in mylonites and nonmylonitized wall rock and modeling of the waveform of the reflectors. This similar conclusion suggests that mechanisms such as the one investigated here may be important in a wide variety of fault systems. We know also that other prisms contain similarly reflective fault zones, and the potential exists, based on these results, to calibrate other even more significant reflectors (such as the Northern Barbados Ridge décollement) to fluid pressure. This study establishes the potential for interpretation of in situ fluid pressure from such seismic reflection images anywhere that fault fabric and lithology are known.

\section{ACKNOWLEDGMENTS}

We thank the ODP marine technicians, especially curator Erinn McCarty, for their patience and assistance during the time-consuming collection of whole-round samples. Walter Schillinger provided invaluable assistance with laboratory instrumentation, for which we are very grateful. We are further indebted to J. Byerlee, Sheila Peacock, and Graham Westbrook for helpful reviews which improved the quality of the manuscript, and to Dan Karig for insightful comments. This study was supported by a JOI/USSAC research fellowship awarded to Tobin, and National Science Foundation grants OCE-9019799, OCE-9116368 (to J.C. Moore), and OCE-9115924 (to G.F. Moore).

\section{REFERENCES}

Bangs, N.L.B., and Westbrook, G.K., 1991. Seismic modeling of the décollement zone at the base of the Barbados Ridge accretionary complex. $J$. Geophys. Res., 96:3853-3866.

Bourbié, T., Coussy, O., and Zinszner, B., 1987. Acoustics of Porous Media: Paris (Ed. Tech.).

Bowers, G.L., 1994. Pore pressure estimation from velocity data: accounting for overpressure mechanisms besides undercompaction. IADC/SPE Drill. Conf. Proc., 515-530.

Bray, C.J., and Karig, D.E., 1985. Porosity of sediments in accretionary prisms, and some implications for dewatering processes. J. Geophys. Res., 90:768-778. 
Brown, K.M., Bekins, B., Clennell, B., Dewhurst, D., and Westbrook, G., 1994. Heterogeneous hydrofracture development and accretionary fault dynamics. Geology, 22:259-262.

Christensen, N.I., 1985. Measurements of dynamic properties of rocks at elevated temperatures and pressures. In Pincus, H.J., and Hoskins, E.R. (Eds.), Measurements of Rock Properties at Elevated Pressures and Temperatures: Philadelphia (Am. Soc. for Testing and Materials), ASTM STP 869:93-107.

Cloos, M., 1984. Landward-dipping reflectors in accretionary wedges: active dewatering conduits? Geology, 12:519-522.

Cochrane, G.R., MacKay, M.E., Moore, G.F., and Moore, J.C., 1994. Consolidation and deformation of sediments at the toe of the central Oregon accretionary prism from multichannel seismic data. In Westbrook, G.K. Carson, B., Musgrave, R.J., et al., Proc. ODP, Init. Repts., 146 (Pt. 1): College Station, TX (Ocean Drilling Program), 421-426.

Davis, D., Suppe, J., and Dahlen, F.A., 1983. The mechanics of fold-andthrust belts. J. Geophys. Res., 88:1153-1172.

Domenico, S.N., 1976. Effect of brine-gas mixture on velocity in an unconsolidated sand reservoir. Geophysics, 41:882-894.

Fertl, W.H., 1976. Abnormal Formation Pressures: Amsterdam (Elsevier).

Gardner, G.H.F., Gardner, L.W., and Gregory, A.R., 1974. Formation velocity and density: the diagnostic basics for stratigraphic traps. Geophysics, 39:770-780.

Hamilton, E.L., 1978. Sound velocity-density relations in sea-floor sediments and rocks. J. Acoust. Soc. Am., 63:366-377.

Hubbert, M.K., and Rubey, W.W., 1959. Role of fluid pressure in mechanics of overthrust faulting, I. Mechanics of fluid-filled porous solids and its application to overthrust faulting. Geol. Soc. Am. Bull., 70:115-166.

Hyndman, R.D., Foucher, J.P., Yamano, M., Fisher, A., Berner, U., Brückmann, W., Byrne, T., Chabernaud, T., Firth, J.V., Gamo, T., Gieskes, J.M., Hill, I.A., Karig, D.E., Kastner, M., Kato, Y., Lallemand, S., Lau, R., Maltman, A.J., Moore, G.F., Moran, K., Olafsson, G., Owens, W.H., Pickering, K., Siena, F., Taira, A., Taylor, E., Underwood, M.B., Wilkinson, C., and Zhang, J., 1992. Deep sea bottom-simulating-reflectors: calibration of the base of the hydrate stability field as used for heat flow estimates. Earth Planet. Sci. Lett., 109:289-301.

Jones, T., and Nur, A., 1984. The nature of seismic reflections from deep crustal fault zones. J. Geophys. Res., 89:3153-3171.

Karig, D.E., 1993. Reconsolidation tests and sonic velocity measurements of clay-rich sediments from the Nankai Trough. In Hill, I.A., Taira, A., Firth, J.V., et al., Proc. ODP, Sci. Results, 131: College Station, TX (Ocean Drilling Program), 247-260.

Karig, D.E., and Lundberg, N., 1990. Deformation bands from the toe of the Nankai accretionary prism. J. Geophys. Res., 95:9099-9109.

Kastner, M., Elderfield, H., and Martin, J.B., 1991. Fluids in convergent margins: what do we know about their composition, origin, role in diagenesis and importance for oceanic chemical fluxes? Philos. Trans. $R$. Soc. London A, 335:243-259.

Kulm, L.D., Prince, R.A., Snavely, P.D., Jr., 1973. Site survey of the Northern Oregon Continental Margin and Astoria Fan. In Kulm L.D., von Huene R., et al., Init. Repts. DSDP, 18: Washington (U.S. Govt. Printing Office), 979-987.

Lundberg, N., and Moore, J.C., 1986. Macroscopic structural features in Deep Sea Drilling Project cores from forearc regions. In Moore, J.C. (Ed.), Structural Fabric in Deep Sea Drilling Project Cores From Forearcs. Mem.-Geol. Soc. Am., 166:13-44.

MacKay, M.E., Moore, G.F., Cochrane, G.R., Moore, J.C., and Kulm, L.D., 1992. Landward vergence and oblique structural trends in the Oregon margin accretionary prism: implications and effect on fluid flow. Earth Planet. Sci. Lett., 109:477-491.

Maltman, A.J., Byrne, T., Karig, D.E., Lallemand, S., Knipe, R., and Prior, D., 1993. Deformation structures at Site 808, Nankai accretionary prism, Japan. In Hill, I.A., Taira, A., Firth, J.V., et al., Proc. ODP, Sci. Results, 131: College Station, TX (Ocean Drilling Program), 123-133.

Moore, G.F., and Shipley, T.H., 1993. Character of the décollement in the Leg 131 area, Nankai Trough. In Hill, I.A., Taira, A., Firth, J.V., et al., Proc. ODP, Sci. Results, 131: College Station, TX (Ocean Drilling Program), 73-82.

Moore, G.F., Shipley, T., Karig, D., and Taira, A., 1990. Structural geometry at the toe of the Nankai accretionary prism from MCS and ESP data. $J$. Geophys. Res., 95:8753-8765

Moore, J.C., Brown, K.M., Horath, F., Cochrane, G., MacKay, M., and Moore, G., 1991. Plumbing accretionary prisms: effects of permeability variations. Philos. Trans. R. Soc. London A, 335:275-288.

Moore, J.C., Moore, G.F., Cochrane, G.R., and Tobin, H.J., in press. Negative-polarity seismic reflections along faults of the Oregon accretionary prism: indicators of overpressuring. J. Geophys. Res.

Moore, J.C., Orange, D., and Kulm, L.D., 1990. Interrelationship of fluid venting and structural evolution: Alvin observations from the frontal accretionary prism, Oregon. J. Geophys. Res., 95:8795-8808.

Moore, J.C., and Vrolijk, P., 1992. Fluids in accretionary prisms. Rev. Geophys., 30:113-135.

Shipley, T.H., Moore, G.F., Bangs, N.L., Moore, J.C., and Stoffa, P.L., 1994. Seismically inferred dilatancy distribution, northern Barbados Ridge décollement: implications for fluid migration and fault strength. Geology, $22: 411-414$

Shipley, T.H., Stoffa, P.L., and Dean, D.F., 1990. Underthrust sediments, fluid migration paths, and mud volcanoes associated with the accretionary wedge off Costa Rica: Middle America trench. J. Geophys. Res., 95:8743-8752.

Sibson, R.H., 1981. Controls on low-stress hydro-fracture dilatancy in thrust, wrench and normal fault terrains. Nature, 289:665-667.

, 1990. Conditions for fault valve behaviour. In Knipe, R.J., and Rutter, E.H. (Eds.), Deformation Mechanisms, Rheology and Tectonics. Geol. Soc. Spec. Publ. London, 54:15-28.

Taylor, E., and Leonard, J., 1990. Sediment consolidation and permeability at the Barbados forearc. In Moore, J.C., Mascle, A., et al., Proc. ODP, Sci. Results, 110: College Station, TX (Ocean Drilling Program), 289308.

Westbrook, G.K., 1991. Geophysical evidence for the role of fluids in accretionary wedge tectonics. Philos. Trans. R. Soc. London A, 335:227-242.

Westbrook, G.K., Carson, B., Musgrave, R.J., et al., 1994. Proc. ODP, Init. Repts., 146 (Pt. 1): College Station, TX (Ocean Drilling Program).

Westbrook, G.K., Ladd, J.W., Buhl, P., Bangs, N., and Tiley, G.J., 1988. Cross section of an accretionary wedge: Barbados Ridge complex. Geology, 16:631-635.

White, R.S., 1977. Seismic bright spots in the Gulf of Oman. Earth Planet. Sci. Lett., 37:29-37.

Date of initial receipt: 6 September 1994

Date of acceptance: 27 February 1995

Ms 146SR-229 